\title{
Mecanismos celulares e moleculares envolvidos no processo de transição dimórfica em fungos patogênicos humanos
}

\author{
Rodrigo da Silva SANTOS ${ }^{1}$ \\ Patrícia de Sousa LIMA ${ }^{2}$ \\ Leonardo Barcelos de PAULA ${ }^{3}$ \\ Angela Adamski da Silva REIS ${ }^{4}$ \\ Mônica Santiago BARBOSA ${ }^{5}$
}

1 - Biólogo. Departamento de Genética/Departamento de Bioquímica e Imunologia, Faculdade de Medicina de Ribeirão Preto, Universidade de São Paulo.

2 - Bióloga. Departamento de Patologia Molecular, Faculdade de Medicina, Universidade de Brasília.

3 - Biólogo. Departamento de Genética, Faculdade de Medicina de Ribeirão Preto, Universidade de São Paulo.

4 - Biomédica. Professora Adjunta do Departamento de Bioquímica e Biologia Molecular, Instituto de Ciências Biológicas, Universidade Federal de Goiás.

5 - Biomédica. Professora Adjunta e Orientadora, Departamento de Ciências Biológicas e da Saúde, Universidade Federal de Goiás, Campus Jataí-GO.

Email: rdssantos@gmail.com (Santos, RS)

Resumo: Os fungos de importância médica em geral podem ter morfologias diferentes durante o seu desenvolvimento. Este fenômeno de variação morfológica mais importante em micologia médica é o dimorfismo, que se caracteriza por ser um processo reversível. O dimorfismo é uma característica fúngica que depende de alterações de temperatura e/ou nutrientes. Estas favorecem a instalação dos fungos e os ajudam a resistir às agressões vindas do hospedeiro. No fungo Paracoccidioides brasiliensis, o dimorfismo não é sempre dependente de temperatura, pois fatores nutricionais também interferem nestes processos. Sendo assim, o objetivo do nosso trabalho é descrever os mecanismos celulares e moleculares envolvidos e caracterizados como essenciais para que a transição dimórfica ocorra e contribua para a progressão do processo infeccioso.

Palavras-Chave: Dimorfismo, temperatura, nutrientes, fungos patogênicos, doenças infecciosas.

\section{Cellular and molecular mechanisms involved in the transition dimorphic process on human pathogenic fungi}

\begin{abstract}
The fungi of medical importance in general may have different morphologies during its development. This phenomenon of morphological variation more important in medical mycology is dimorphism, which is characterized by a reversible process. The fungal dimorphism is a characteristic that depends on temperature changes and /or nutrients. These favor the installation of fungi and help to resist the aggression coming from the host. In Paracoccidioides brasiliensis dimorphism is not always dependent on temperature, as nutritional factors also interfere in these processes. Therefore, the aim of our study is to describe the cellular and molecular mechanisms involved and characterized as essential for the dimorphic transition occurs and contributes to the progression of the infection.
\end{abstract}

Keywords: Dimorphism, temperature, nutrients, pathogenic fungi, infectious diseases. 


\section{A Transição Dimórfica em Fungos Patogênicos}

A diferenciação celular é um processo geral que pode ser observada desde organismos mais simples até eucariotos superiores. Em fungos dimórficos, o processo de diferenciação celular pode promover a formação de várias estruturas como, por exemplo, a formação de esporos, a transição da forma de micélio para levedura ou, ainda, a formação de estruturas de infecção, tais como apressórios em fungos fitopatogênicos.

O dimorfismo é um processo de adaptação a mudanças ambientais observado em diversos fungos patogênicos ou não. Essa adaptação implica na transformação de células filamentosas (hifas ou pseudohifas) em células leveduriformes. Em alguns fungos o processo inverso também é possível, como em Saccharomyces cerevisiae. Esses fungos têm a diferença da temperatura como principal fator da mudança de suas formas (Daher, 2005a).

A família Ascomicota possui seis espécies de fungos dimórficos filogeneticamente relacionados: Blastomyces dermatitidis, Coccidioides immitis, Histoplasma capsulatum, Paracoccidioides brasiliensis, Sporothrix schenkii e Penecillium marnefiii. Esses patógenos são capazes de se converterem da forma não patogênica do solo (hifas) para a patogênica leveduriforme nos pulmões de humanos ou de outros hospedeiros mamíferos. A importância biológica dessa fase de transição é exatamente requerida para virulência dos mesmos. O morfotipo das células fúngicas encontradas no ambiente diferem do morfotipo de levedura patogênica não somente no perfil ou aspecto celular, mas também na composição da parede celular, da presença de moléculas antigênicas e na expressão de fatores de virulência. Adicionalmente, as células se adaptam a mudanças da temperatura ocorrendo múltiplas mudanças na composição lipídica da membrana plasmática no qual se dá o remodelamento e reorganização da membrana (Nemecek et al, 2006).

$\mathrm{Na}$ transição dimórfica ocorrem expressões de genes específicos para virulência e patogenicidade. Genes estágio-específicos são necessários para a manutenção da forma, bem como para a adaptação às novas condições ambientais. Por isso, a identificação de genes diferencialmente expressos em fungos é de fundamental importância para uma melhor compreensão dos mecanismos moleculares envolvidos no dimorfismo (Tebbets \& Klein, 2007).

As mudanças ambientais, principalmente a temperatura, resultam em mudanças da forma do fungo encontrada no solo e da infectante, leveduriforme. Em B.dermatitidis, as análises revelaram que essa mudança ocasionou um aumento do componente da parede celular, o $\alpha$-1,3-glucana, 
e a diminuição de $\beta$-1,3-glucana, também componente desta parede. Na maioria dos fungos patogênicos, como também o $H$. capsulatum e $P$. brasiliensis, o nível de $\alpha$-1,3glucana se relaciona com a virulência do fungo. Ainda em B.dermatitidis, foi detectado que somente na fase de levedura, infectante, que há expressão da proteína BAD1( formalmente denominada WI-1). Essa proteína se liga à actina na parede celular do fungo funcionando como uma molécula de adesão na superfície, sendo um essencial fator de virulência. Esta molécula se liga a receptores tipo 3 e CD4 dos macrófagos e tecido dos pulmões no hospedeiro (Nemecek et al, 2006).

O gene ags 1 que codifica para a enzima a-1,3-glucana sintase responsável pela produção do polímero $\alpha$-1,3-glucana foi silenciado, em H.capsulatum, por interrupção da sua expressão através de silenciamento do gene com RNA de interferência. Os estudos demonstraram que um prejudicial crescimento das leveduras em macrófagos, in vitro, foi significante e que suas habilidades de colonização nos pulmões de ratos foram também diminuídas. Além disso, somente na fase de levedura patogênica, há expressão de uma proteína que se liga ao cálcio denominada CBP1, sendo essencial no crescimento de suas células nos macrófagos in vitro e sobrevivência no hospedeiro e patogenicidade in vivo. Produz ainda outra proteína que não é produzida na fase de micélio que é a YPS3, localizada na parede celular. O resultado do experimento que interrompeu a expressão dessa proteína por RNA de interferência, foi o significante crescimento prejudicado desse fungo nos pulmões e baço de murinos, indicando que a expressão é requerida para virulência (Nemecek et al, 2006).

Em Coccidioides immitis a identificação de uma adesina fase específica parasítica foi alcançada na procura por moléculas de virulência. A SOWgp é essa adesina presente nos esporos de C.immitis que se liga às proteínas da matriz extracelular das células hospedeiras sendo importante tanto para sobrevivência quanto para sua patogênese. Em Penecillium marnefiii a peroxidase catalase foi encontrada e se relaciona a uma maior expressão na fase de levedura do fungo devido à necessidade de possível degradação do peróxido de hidrogênio no qual o fungo é mais exposto durante a transição dimórfica. Foram identificados genes envolvidos no metabolismo de sulfúricos sendo altamente regulados na fase leveduriforme. Esse foi um grande trunfo devido a estudos recentes demonstrarem que os metabólicos sulfurados são de grande importância para o estado morfológico de H.capsulatum e de outros fungos dimórficos (Nemecek et al, 2006).

Em P. brasiliensis o estudo dos transcritos mais expressos nas diferentes formas 
do fungo levou a um perfil analisado do trancriptoma do fungo. Foram identificados 328 genes diferencialmente expressos durante a fase de transição sendo 58 na fase miceliana e 270 na leveduriforme. Esses genes altamente regulados estão envolvidos com ciclo celular, resposta a estresses, resistências a drogas e vias de transdução de sinal (Tebbets \& Klein, 2007).

Recentemente foi descoberto um regulador global responsável pelo dimorfismo e virulência de B.dermatitidis e $H$. capsulatum chamado Híbrido Histidina Kinase (DRK1). Esse modulador foi requerido para a fase de transição do fungo - fase não patogênica para patogênica - tendo influência na expressão de genes de virulência e na patogenicidade in vivo (Nemecek et al, 2006).

\section{O Dimorfismo em $P$. brasiliensis: uma análise rigorosa e uma compreensão mais ampla}

\section{O fungo $P$. brasiliensis apresenta} dimorfismo térmico, ou seja, a característica de alternar-se entre duas formas morfológicas, em resposta a ambientes hostis. O dimorfismo é considerado um mecanismo de defesa importante para a adaptação de fungos às condições adversas do hospedeiro humano, à invasão de tecidos e ao estabelecimento da doença (Kurokawa et al., 1998; San-Blas et al., 2002).
A temperatura é um dos estímulos mais notórios no dimorfismo do fungo $P$. brasiliensis, que se apresenta como micélio a $22^{\circ} \mathrm{C}-25^{\circ} \mathrm{C}$ e como levedura a $35^{\circ} \mathrm{C}-37^{\circ} \mathrm{C}$ (SanBlas, 2002). Fatores nutricionais também podem interferir no processo dimórfico de $P$. brasiliensis. A adição de soro fetal bovino à meio de cultura complexo e quimicamente definido permitiu preservar a expressão fenotípica de leveduras, a $25^{\circ} \mathrm{C}$ (Villar et al., 1988). Outro fator que foi relacionado ao dimorfismo de $P$. brasiliensis é a presença do hormônio feminino 17- $\beta$-estradiol. O hormônio inibe in vitro e in vivo a transição de micélio para levedura, de maneira dose-dependente, sendo esse fato relacionado como possível fator de proteção à infecção em mulheres (Restrepo et al., 1984; Sano et al., 1999).

Silva et al., (1994) caracterizaram in vitro o processo de diferenciação do isolado Pb01 (ATCC-MYA-826), e demonstraram que a diferenciação de micélio para levedura, e o inverso, ocorrem em 20 e 15 dias, respectivamente, após a alteração da temperatura de cultivo. Em ambos, ocorre um período de latência que se dá entre 48-72 horas, atingindo 70-80\% de diferenciação no décimo dia, o que caracteriza o processo de dimorfismo in vitro de $P$. brasiliensis como sendo lento e gradual.

Visto que a eficiência de instalação de P. brasiliensis no hospedeiro se dá pela transição da forma miceliana (infectante), para 
a leveduriforme (patogênica), o estudo de genes/proteínas com expressão diferencial durante a transição dimórfica do fungo, foi alvo de estudo de diferentes grupos. Nesse sentido, Silva et al. (1994), avaliaram a transição celular no isolado $P b 01$, caracterizada por alterações na síntese de proteínas durante os estágios iniciais do processo de diferenciação. Cunha et al. (1999), detectaram proteínas diferencialmente expressas em P. brasiliensis. Particularmente, destacam-se a $P b \mathrm{M} 46$ similar à enolases (46 $\mathrm{kDa}$, presente em maior quantidade na fase miceliana) e PbY20 (proteína de $20 \mathrm{kDa}$ presente somente na fase leveduriforme). $\mathrm{O}$ gene codificante para a $P b Y 20$ foi caracterizado; a análise comparativa da sequiência deduzida de aminoácidos mostrou identidade alta da $\mathrm{PbY} 20$ com flavodoxinas, que são proteínas que se ligam à coenzima FMN (flavina mononucleotídeo), transferindo elétrons (Daher et al., 2005b).

Fonseca et al. (2001), através de estudos de imunoproteômica, caracterizaram sequiências parciais de aminoácidos dos antígenos catalase, frutose-1-6-bifosfato aldolase, malato desidrogenase, triose fosfato isomerase $\mathrm{e}$ gliceraldeído-3-fosfato desidrogenase, todos preferencialmente expressos na forma leveduriforme de $P$. brasiliensis. Os genes correlatos foram posteriormente caracterizados e, como previsto, apresentaram expressão diferencial durante a transição dimórfica do fungo (Moreira et al., 2004; Pereira et al., 2004;
Barbosa et al., 2004; Carneiro et al., 2005). Além disso, os genes codificantes das proteínas HSP70 (Silva et al., 1999), HSP60 (SalemIzacc et al., 2001), ClpB (Jesuino et al., 2002), manosiltransferase (Costa et al., 2002), apresentam baixos níveis de expressão na forma miceliana, quando comparados com a forma de levedura de $P$. brasiliensis, sugerindo que estas proteínas sejam necessárias para sobrevida do fungo nas condições térmicas do hospedeiro e que possam desempenhar papel na morfogênese de $P$. brasiliensis.

O Projeto Genoma Funcional e Diferencial de $P$. brasiliensis, desenvolvido por pesquisadores da região Centro-Oeste do Brasil, resultou no seqüenciamento de 6.022 genes expressos nas fases miceliana e leveduriforme do isolado $P b 01$, possibilitando a detecção de genes diferencialmente expressos (Felipe et al., 2003; 2005). A diferenciação celular em $P$. brasiliensis requer mudança na temperatura, o que pode ser associado com a resposta ao estresse. Dessa forma, foram identificados 48 transcritos codificando chaperonas ou proteínas envolvidas no processo de estresse, sendo oito desses transcritos diferencialmente expressos. A análise do transcriptoma também revelou alguns prováveis componentes das vias de sinalização e seqüências gênicas consideradas como potenciais alvos para drogas antifúngicas em $P$. brasiliensis, não possuindo nenhum homólogo no genoma humano, como: quitina deacetilase, isocitrato liase e $\alpha$-1,3-glicana 
sintase, todos preferencialmente expressos na fase leveduriforme.

Outro projeto Genoma Funcional foi desenvolvido por pesquisadores do Estado de São Paulo, que identificaram 4.692 genes do isolado $P b 18$. Através da análise de ESTs, Goldman et al. (2003), identificaram vários genes potenciais de virulência em $P$. brasiliensis homólogos à C. albicans. Os genes da via de transdução de sinal foram implicados na transição dimórfica. A identificação de alguns genes de $P$. brasiliensis homólogos aos genes envolvidos na via de transdução de sinal e relacionados à virulência de $C$. albicans, sugere que esta via possa estar atuando em $P$. brasiliensis, provavelmente controlando a diferenciação celular. Marques et al. (2004), utilizando biblioteca de subtração e microarranjos, identificaram genes preferencialmente expressos na fase leveduriforme de $P$. brasiliensis (isolado $\mathrm{Pb} 18$ ), proporcionando maiores informações acerca da patobiologia deste fungo. Dentre os genes identificados como diferencialmente expressos estão $\quad \alpha$-1,3-glucana sintetase, enzima relacionada ao metabolismo de parede celular; ERG25 que codifica uma C-4 esterol metil oxidase e atua no primeiro passo enzimático da síntese de ergosterol em fungos, além de genes envolvidos no metabolismo de enxofre, tais como metionina permease. A análise do transcriptoma de $P$. brasiliensis durante a transição dimórfica é atualmente objeto de estudo de pesquisadores (Nunes et al., 2005; Bastos et al., 2007).

Nunes et al. (2005), através de microarranjos de DNA, avaliaram a expressão de genes de $P$. brasiliensis durante a transição de micélio para levedura. Nesse estudo foram identificados vários genes diferencialmente expressos durante a transição morfológica. Estão inclusos entre esses, genes que codificam enzimas envolvidas no metabolismo de aminoácidos, transdução de sinal, síntese de proteínas, metabolismo da parede celular, estrutura do genoma, resposta ao estresse oxidativo, controle do crescimento e desenvolvimento do fungo $P$. brasiliensis. Durante a transição da fase miceliana para leveduriforme de $P$. brasiliensis verificou-se a expressão alta do gene que codifica para uma 4hidroxil-fenil-piruvato dioxigenase (4-HPPD), proteína envolvida no catabolismo de aminoácidos. Este gene pode ser inibido pela adição de NTBC [2-(2-nitro-4trifluorometilbenzoil)-ciclohexane-1,3-dione], assim como por seus derivados. A inibição de 4-HPPD provoca o bloqueio do crescimento e da diferenciação para a fase leveduriforme do fungo in vitro.

A via da biossíntese do enxofre foi amplamente estudada em fungos (Marzluf, 1997; Thomas \& Surdin-Kerjan, 1997; Paszewski et al., 2000). Recentemente, a análise da expressão de genes envolvidos na utilização de enxofre foi realizada em $P$. 
brasiliensis (Andrade et al., 2006; Ferreira et al., 2006). Neste estudo, os pesquisadores caracterizaram a expressão de cinco genes envolvidos no metabolismo do enxofre (CDI1cisteína dioxigenase, MEP1-metionina permease, CHS1-colina sulfatase, APS1-APS kinase, SUR1-sulfito redutase) e avaliaram o acúmulo de RNAm destes genes durante a transição de micélio para levedura e crescimento da fase leveduriforme. Todos os cincos genes avaliados neste estudo apresentaram um alto acúmulo de RNAm durante a transição dimórfica e durante o crescimento da fase leveduriforme, sugerindo que nestas situações estão ocorrendo mobilização e armazenamento de enxofre, além da ativação da via de assimilação inorgânica. Os autores sugerem que, embora $P$. brasiliensis não use enxofre inorgânico como única fonte para iniciar a transição e o crescimento da fase leveduriforme, este fungo pode de algum modo, utilizar ambas, as vias orgânica e inorgânica durante o processo de crescimento. Estes estudos forneceram novas informações sobre o comportamento transcricional de vários genes envolvidos no metabolismo do enxofre.

O perfil transcricional de $P$. brasiliensis durante a diferenciação morfológica de micélio para levedura foi avaliado por Bastos et al. (2007). Vários genes potencialmente relacionados com a síntese de membrana e parede celulares mostraram-se aumentados durante a diferenciação celular de micélio para levedura após 22 horas de indução da transição, sugerindo que $P$. brasiliensis favorece o remodelamento da membrana e de parede celulares nos estágios iniciais da morfogênese. Neste estudo, genes envolvidos na via de assimilação do enxofre como a sulfito redutase, mostraram-se superexpressos durante a transição, sugerindo o envolvimento do metabolismo do enxofre durante o processo de diferenciação em P. brasiliensis, como descrito anteriormente. Durante a transição também foi verificada a presença de enzimas que participam do ciclo do glioxalato, como a isocitrato liase, malato desidrogenase, citrato sintase e aconitase. A presença destes transcritos durante a diferenciação indica que esta via é funcional durante esse processo. Também foram identificados genes envolvidos em vias de transdução de sinal tais como MAPK, serina/treonina quinase e histidina quinase, sugerindo que a transição morfológica em $P$. brasiliensis é mediada por vias de transdução de sinal que controlam a adaptação ao ambiente para a sobrevivência e adaptação do fungo dentro do hospedeiro.

Com o objetivo de estudar genes possivelmente envolvidos na adaptação e sobrevivência de $P$. brasiliensis no hospedeiro durante a infecção, Bailão et al. (2006), utilizaram a Análise de Diferença Representacional de cDNA (cDNA-RDA) para identificar genes de $P$. brasiliensis induzidos durante o processo infectivo e em condições 
que mimetizam a via hematológica de disseminação fúngica. No modelo de infecção experimental foi observada a alta frequência do transcrito zrtl (zinco/ferro permease). O mesmo foi observado para o transcrito $c t r 3$, codificando um transportador de cobre de alta afinidade, que sugere a exigência de uma permease cobre/ferro para o transporte do Fe. Em adição, o transcrito codificante para a glutamina sintase $(g \ln 1)$ foi fortemente induzido após incubação com sangue humano sugerindo que a remodelação na parede/membrana celular possa ser um dos meios pelos quais $P$. brasiliensis responda às mudanças de osmolaridade externa encontrada pelo fungo na via de disseminação sanguínea.

Bailão et al. (2007), analisaram genes preferencialmente expressos em leveduras de $P$. brasiliensis tratadas com plasma humano, simulando assim sítios de infecção, com inflamação. Foi observado um aumento significativo na expressão de transcritos super regulados, associados com a degradação de ácido graxos, síntese de proteínas envolvidas no remodelamento da parede celular e síntese de proteínas relacionadas à mudança de osmolaridade. Assim como na incubação com sangue, a glutamina sintase também é super expressa na condição de incubação com plasma, reforçando a hipótese já descrita anteriormente de que a super expressão desta enzima esteja ligada ao aumento da síntese de quitina que ocorreria durante o estresse osmótico. As análises comparativas dos perfis de genes super regulados durante a incubação com plasma e com sangue demonstraram que aproximadamente $16,6 \%$ dos transcritos super regulados encontrados no fungo quando na presença de plasma humano não estavam presentes no sangue, sugerindo a influência das células sanguíneas no perfil transcricional previamente descrito por Bailão et al. (2006).

Tavares et al. (2007), realizaram experimentos de hibridização em microarranjos de DNA, nos quais foi possível definir transcritos de $P$. brasiliensis, isolado $P b 01$, internalizados em macrófagos de origem murina. Este fungo possui inúmeros processos adaptativos ao hospedeiro em resposta à fagocitose. Após a internalização, o patógeno promove adaptação metabólica induzindo a expressão de genes da biossíntese de aminoácidos, especificamente genes envolvidos na biossíntese de metionina, além de diversos genes relacionados ao estresse como, por exemplo, a superóxido dismutase 3, Hsp60 e QCR8 (subunidade do citocromo oxidase c).

Recentemente, o transcriptoma de $P$. brasiliensis, fase leveduriforme, recuperado de fígado de animais experimentais (camundongos B10) foi descrito por Costa et al. (2007). Foram seqüenciadas 4.932 ESTs no processo infectivo, sendo $37,47 \%$ relacionadas a novos genes e $23,75 \%$ pertencentes a genes super expressos. Os genes identificados foram categorizados em processos metabólicos, transporte celular e 
energia. Do total de ESTs geradas neste estudo, $65,53 \%$ das sequiências identificadas, também estavam presentes no transcriptoma de levedura e micélio de células obtidas de cultura in vitro, descrito por Felipe et al. (2005). A demonstração do perfil gênico das células leveduriformes de $P$. brasiliensis recuperadas de animais infectados é um requisito essencial para o estudo do genoma funcional de modo a esclarecer os mecanismos de patogenicidade e virulência fúngica.

\section{Conclusão}

A mudança morfológica das formas fúngicas não-patogênicas para as patogênicas, leveduriformes, é essencial para a virulência dos fungos aqui apresentados, ou seja, fungos dimórficos patogênicos. Essa mudança permite que o fungo se adapte às condições ambientais das células hospedeiras e tenha sucesso na propagação da doença. Genes de virulência são ativados e proteínas específicas, mais expressas. Atualmente, muitos desses genes e proteínas têm sido estudados permitindo melhor entendimento dos processos patogênicos desses microrganismos, além do aperfeiçoamento de novas ferramentas em biologia molecular, tais como: as técnicas de manipulação gênica, RNA de interferência e microarranjos. Assim, esses estudos têm sido alvos potenciais na obtenção de novos fármacos antifúngicos, pois pesquisas nessa área, além de contribuírem na exploração da diferenciação celular desses patógenos em seus hospedeiros, aumentam o conhecimento dos genes e a caracterização funcional das suas proteínas, presumindo a função das mesmas durante o processo de instalação e manutenção da infecção.

\section{Referências Bibliográficas}

ANDRADE R. V, PAES H. C, NICOLA A. M, CARVALHO M. J, FACHIN A. L, CARDOSO R. S, SILVA S. S, FERNANDES L, SILVA S. P, DONADI E. A, SAKAMOTO-HOJO E. T, PASSOS G. A, SOARES C. M, BRIGIDO M. M, FELIPE M. S. S. Cell organization, sulphur metabolism and ion transport-related genes are differentially expressed in Paracoccidioides brasiliensis mycelium and yeast cells. BMC Genomics 7: 208-221, 2006.

BAILAO A. M, SCHRANK A, BORGES C. L, DUTRA V, WALQUIRIA INES MOLINARIMADLUM E. E, SOARES FELIPE M. S.S, MENDES-GIANNINI M. J, MARTINS W. S, PEREIRA M, SOARES C. M. A. Differential gene expression by Paracoccidioides brasiliensis in host interaction conditions: Representational difference analysis identifies candidate genes associated with fungal pathogenesis. Microbes Infect. Oct; 8(1213):2686-97, 2006.

BAILÃO A. M, SHRANK A, DUTRA V, FELIPE M. S. S, FIÚZA R. B, BORGES C. L, PEREIRA M, SOARES C. M. A. 2007. The transcriptional profile of Paracoccidioides brasiliensis yeast cells is influenced by human plasma. FEMS Immunol Med Microbiol, 2007.

BARBOSA, M. S.; PASSOS-CUNHA, D.A.; FELIPE, M.S.S.; JESUINO, R.S.A.; PEREIRA, M.; SOARES, C.M.A. The glyceraldehydes-3- 
phosphate dehydrogenase is differentially regulated in phases of Paracoccidioides brasiliensis: Molecular and phylogenetic analysis. Fungal Genet Biol., v.41, p.667-675., 2004.

BASTOS K. P, BAILÃO A. M, BORGES C. L, FARIA F. P, FELIPE M. S. S, SILVA M. G, MARTINS W. S, FIÚZA R. B, PEREIRA M, SOARES C. M. A. The transcriptome analysis of early morphogenesis in Paracoccidioides brasiliensis mycelium reveals up regulated and novel genes potentially associated to the dimorphic process. BMC Microbiol, 10;7:29, 2007.

CARNEIRO, L.C.; FARIA, F.P.; FELIPE, M.S.S.; PEREIRA, M. SOARES, C.M.A. 2005. Paracoccidioides brasiliensis presents two different cDNAs encoding homologues of the fructose 1,6-biphosphate aldolase: Protein isolation, cloning of the cDNAs and genes, structural, phylogenetic and expression analysis. Fungal Gen. Biol., 42 (1): 51-60, 2005.

COSTA A.A., GOMEZ F.J., PEREIRA M., FELIPE M.S., JESUINO R.S., DEEPE G.S. JR, SOARES C.M. A. Characterization of a gene which encodes a mannosyltransferase homolog of Paracoccidioides brasiliensis. Microbes Infect. 4: 1027-1034, 2002.

COSTA M., BORGES C. L., BAILÃO A. M., MEIRELLES V G., MENDONÇA Y. A., DANTAS S. F. I. M., FARIA F. P., FELIPE M. S. S. , MOLINARI-MADLUM E. E. W. I, MENDES-GIANNINI M. J. S, FIÚZA R. B., MARTINS W. S., PEREIRA M E SOARES C. M. A. Transcriptome profiling of Paracoccidioides brasiliensis yeast cells recovered from infected mice bring new insight into fungal response upon host-interaction. Microbiology. 2007.

CUNHA A.F., SOUSA M.V., SILVA S.P., JESUINO R.S., SOARES C.M. A., FELIPE M.S. Identification, N-terminal region sequencing and similarity analysis of differentially expressed proteins in

Paracoccidioides brasiliensis. Med Mycol 37: 115-121, 1999.

DAHER, BS. O gene de expressão diferencial $P b$ Y 20 do fungo Paracoccidioides brasiliensis. 2005.162 f. Tese (Doutorado em Ciências Biológicas- Biologia Molecular) - Instituto de Ciências Biológicas, Universidade de Brasília, Brasília, 2005a.

DAHER B. S, VENANCIO E. J, DE FREITAS S. M, BÁO S. N, VIANNEY P. V, ANDRADE R. V, DANTAS A. S, SOARES C. M, SILVAPEREIRA I, FELIPE M. S. S. The highly expressed yeast gene pby20 from Paracoccidioides brasiliensis encodes a flavodoxin-like protein. Fungal Gen. Biol., 42(5):434-43, $2005 \mathrm{~b}$.

FELIPE M. S, ANDRADE R. V, ARRAES F. B, NICOLA A. M, MARANHÃO A. Q, TORRES F. A, SILVA-PEREIRA I, PbGENOME NETWORK, et al., Transcriptional profiles of the human pathogenic fungus Paracoccidioides brasiliensis in mycelium and yeast cells. J Biol Chem 280: 24706-24714, 2005.

FELIPE M.S., ANDRADE R.V., PETROFEZA S.S., MARANHAO A.Q., TORRES F.A., ALBUQUERQUE P., ARRAES F.B., et al., Transcriptome characterization of the dimorphic and pathogenic fungus Paracoccidioides brasiliensis by EST analysis. Yeast, 20: 263-271, 2003.

FERREIRA M.E.S, MARQUES E.R, MALAVAZI I, TORRES I, RESTREPO A, NUNES L.R, OLIVEIRA R.C, GOLDMAN M.H, GOLDMAN G.H. Transcriptome analysis and molecular studies on sulphur metabolism in the human pathogenic fungus Paracoccidioides brasiliensis. Mol Genet Genomics 276: 450463, 2006.

FONSECA C.A., JESUINO R.S., FELIPE M.S., CUNHA D.A., BRITO W.A., SOARES C.M. Two-dimensional electrophoresis and 
characterization of antigens from

Paracoccidioides brasiliensis. Microbes Infect 3: 535-542, 2001.

GOLDMAN G.H, DOS REIS MARQUES E., DUARTE RIBEIRO D.C., DE SOUZA BERNARDES L.A., QUIAPIN A.C., VITORELLI P.M., SAVOLDI M., SEMIGHINI C.P., DE OLIVEIRA R.C., NUNES L.R., TRAVASSOS L.R., PUCCIA R., BATISTA W.L., FERREIRA L.E., MOREIRA J.C., BOGOSSIAN A.P., TEKAIA F., NOBREGA M.P., NOBREGA F.G., GOLDMAN M.H. Expressed sequence tag analysis of the human pathogen Paracoccidioides brasiliensis yeast phase: identification of putative homologues of Candida albicans virulence and pathogenicity genes. Eukaryot Cell 2: 34-48, 2003.

JESUINO R.S., AZEVEDO M.O., FELIPE M.S.S., PEREIRA M., SOARES C.M.A. Characterization of a chaperone ClpB homologue of Paracoccidioides brasiliensis. Yeast 19: 963-972, 2002.

MARQUES E.R, FERREIRA M.E, DRUMMOND R.D, FELIX J.M, MENOSSI M, SAVOLDI M, TRAVASSOS L.R, PUCCIA R, BATISTA W.L, CARVALHO K.C, GOLDMAN M.H, GOLDMAN GH. Identification of genes preferentially expressed in the pathogenic yeast phase of Paracoccidioides brasiliensis, using suppression subtraction hybridization and differential macroarray analysis. Mol Genet Genomics 271:667-677, 2004.

MARZLUF G.A 1997. Molecular genetics of sulfur assimilation in filamentous fungi and yeast. Annu Rev Microbiol 51:73-96.

MOREIRA, S.F.I.; BAILÃO, A.M.; BARBOSA, M.S.; JESUÍNO, R.S.A.; FELIPE, M.S.S.; PEREIRA, M.; SOARES, C.M.A. Monofunctional catalase $\mathrm{P}$ of Paracoccidioides brasiliensis: identification, characterization, molecular cloning and expression analysis. Yeast, v.30, p.173-182, 2004.
NEMECEK, J.C.; WUTHRICH, M.; KLEIN, B.S. Global control of dimorphism and virulence in fungi. 2006. Science .312:583588.

NUNES L.R, COSTA DE OLIVEIRA R, LEITE D.B, DA SILVA V.S, DOS REIS MARQUES E, DA SILVA FERREIRA M.E, RIBEIRO DC, DE SOUZA BERNARDES L.A, GOLDMAN M.H, PUCCIA R, TRAVASSOS L.R, BATISTA W.L, NOBREGA M.P, NOBREGA F.G, YANG D.Y, DE BRAGANCA PEREIRA C.A, GOLDMAN G.H. Transcriptome analysis of Paracoccidioides brasiliensis cells undergoing mycelium-to-yeast transition. Eukaryot Cell 4: 2115-2128, 2005.

PANCHOLI V, G. S. CHHATWAL. Housekeeping enzymes as virulence factors for pathogens. Int. J. Med. Microbiol. 293; 391401, 2003.

PASZEWSKI A, NATORV R, PIOTROWSKA M, BRZYWCZY J, SIENKO M, GRYNBERG M, PIZZININI E, TURNER G. Regulation of sulfur amino acid biosynthesis in Aspergillus nidulans: physiological and genetical aspects. In: C Brunold (ed) Sulfur nutrition and sulfur assimilation in higher plants. Paul Haupt, Switzerland, p. 93-105, 2001.

PEREIRA, L.A.; PEREIRA, M.; FELIPE, M.S.S.; ZANCOPÉ-OLIVEIRA, R.M.; SOARES, C.M.A. Proteomic identification, nucleotide sequence, heterologous expression and immunological reactivity of the triosephosphate isomerase of Paracoccidioides brasiliensis. Microbes Infect. 6(10) 892-900, 2004.

SALEM-IZAAC, S.M.; GÓMEZ, J.; JESUÍNO, R.S.A.; FONSECA, C.A.; PEREIRA, M.; FELIPE, M.S.S.; DEEPE, G.S.J.; SOARES, C.M.A. Molecular Cloning, Characterization and expression of a Gene Encoding the Heat Shock Protein 60 from Paracoccidioides brasiliensis. Med. Mycol., v.39, p.445-455, 2001. 
SAN-BLAS, G.; NINO-VEGA, G.;

ITURRIAGA, T. Paracoccidioides brasiliensis

and paracoccidioidomycosis: Molecular

approaches to morphogenesis, diagnosis,

epidemiology, taxonomy and genetics. Med.

Mycol., v.40, p.225-242, 2002.

SANO A, NISHIMURA K, MIYAJI M. The

research encouragement award. Effects of sex

hormone on sexual difference of experimental

paracoccidioidomycosis. Nippon Ishinkin

Gakkai Zasshi 40: 1-8,1999.

SILVA, S.P.; BORGES-WALMSLEY, M. I.;

PEREIRA, I. S.; SOARES, C. M. A.;

WALMSLEY, A. R. AND FELIPE, M. S. S.

Differential expression of an HSP 70 during

transition from the mycelial to the infective

yeast form of the human pathogenic fungus

Paracoccidioides brasiliensis. Mol. Microbiol.

31: 1039-1050, 1999.

TAVARES A. H.F.P, SILVA S. S, DANTAS

A.C, CAMPOS E.G, ANDRADE R.V, MARANHÃO A.P, BRÍGIDO M.M, PASSOS-

SILVA D. G, FACHIN A. L, TEIXEIRA S. M.

R, PASSOS G. A. S, SOARES C.M.A,

BOCCA A. L, CARVALHO M. J. A, SILVA-

PEREIRA I, FELIPE M. S. S. Early

transcriptional response of Paracoccidioides

brasiliensis upon internalization by murine

macrophages. Microbes Infect 9: 583-590,

2007.

TEBBETS, B.;KLEIN, B.S. Dimorphism and virulence in fungi. Current Opinion in

Microbiology, 2007.

THOMAS D, SURDIN-KERJAN Y.

Metabolism of sulfur amino acids in $\mathrm{i}$

Microbiol. Mol Biol Rev 61: 503-532, 1997. 